\title{
The triterpenoid lupeol attenuates allergic airway inflammation in a murine model
}

\author{
J.F. Vasconcelos ${ }^{a}$, M.M. Teixeira ${ }^{b}$, J.M. Barbosa-Filho ${ }^{c}$, \\ A.S.S.C. Lúcio ${ }^{c}$, J.R.G.S. Almeida ${ }^{d}$, L.P. de Queiroz ${ }^{\mathrm{e}}$, \\ R. Ribeiro-dos-Santos ${ }^{a}$, M.B.P. Soares ${ }^{a, *}$
}

a Centro de Pesquisas Gonçalo Moniz, Fundação Oswaldo Cruz, Salvador, BA, Brazil

b Instituto de Ciências Biomédicas, Universidade Federal de Minas Gerais, Belo Horizonte, MG, Brazil

c Laboratório de Tecnologia Farmacêutica, Universidade Federal da Paraíba, João Pessoa, PB, Brazil

' Colegiado do Curso de Medicina, Universidade Federal do Vale do São Francisco, Petrolina, PE, Brazil

e Departamento de Ciências Biológicas, Universidade Estadual de Feira de Santana, Feira de Santana, BA, Brazil

Received 28 March 2008; received in revised form 22 April 2008; accepted 24 April 2008

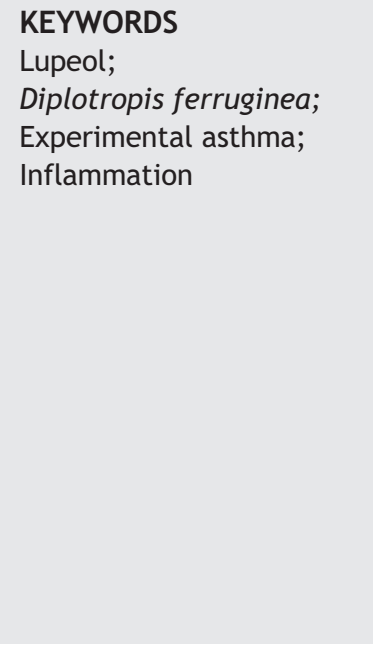

\begin{abstract}
Asthma is a chronic inflammatory disease of the airways associated with a Th2 immune response. Despite their side effects, corticosteroids are the most used and effective drugs for treatment of asthma. In this work we investigated the efficacy of lupeol, a triterpenoid isolated from Diplotropis ferruginea Benth. (Fabaceae), in the treatment of bronchial asthma in BALB/c mice immunized with ovalbumin. Administration of lupeol caused the reduction of cellularity and eosinophils in the bronchoalveolar lavage fluid. Treatment with lupeol also reduced the production of mucus and overall inflammation in the lung. Levels of Type II cytokines IL-4, IL-5 and IL-13 were significantly reduced in mice treated with lupeol, an effect that was similar to that observed in dexamethasone-treated mice. In contrast, IgE production was not significantly altered after treatment with lupeol. In conclusion, our results demonstrate that lupeol attenuates the alterations' characteristics of allergic airway inflammation. The investigation of the mechanisms of action of this molecule may contribute for the development of new drugs for the treatment of asthma.

(c) 2008 Elsevier B.V. All rights reserved.
\end{abstract}

\footnotetext{
* Corresponding author. Fundação Oswaldo Cruz, Centro de Pesquisas Gonçalo Moniz, Laboratório de Engenharia Tecidual e Imunofarmacologia, Rua Waldemar Falcão, 121, Candeal, 40296-750 - Salvador, Bahia - Brazil. Tel.: +55 713176 2260; fax: +55 7131762272.

E-mail address: milena@bahia.fiocruz.br (M.B.P. Soares).
}

\section{Introduction}

The incidence of allergic diseases has increased considerably in recent decades, particularly in developed countries [1]. Asthma is an allergic disease associated with a wide range of signs and symptoms, including wheezing, cough, chest 
tightness, and shortness of breath [2,3]. The medical cost for treating asthmatic patients is high and on the increase [4]. Th2 cells are involved in the asthmatic response by releasing cytokines that are involved in the production of IgE [5-7]. While the exact etiology of asthma is still unknown, it is a clearly multifactorial pathology involving possible genetic predisposition coupled with exposure to certain environmental triggers [1]. The symptoms manifest as a result of airway inflammation, and exacerbations of bronchial asthma involve both episodic airway obstruction and marked airway inflammation $[2,8]$. All this together leads to marked airway oedema, impaired mucociliary function, and further impaired movement of airflow. If the latter changes persist, the inflammation associated with asthma can damage the respiratory epithelium and lead to remodeling of the airways [9-11].

Corticosteroids are the most commonly used drugs and have measurable effects on symptoms, lung function, bronchial responsiveness, and inflammation associated with asthma [12-14]. Side effects of chronic corticosteroid use include osteopenia, poor wound healing, hyperglycemia, hypertension and cataracts, and limit systemic administration $[15,16]$. Thus, the finding of substances with similar ability to limit inflammation associated with asthma but with no or lower toxicity is of great interest [17-19].

Medicinal plants are alternative options to conventional therapies to many diseases, and Brazil with its enormous biodiversity can contribute to the search of new natural products and bioactive molecules. Diplotropis ferruginea Benth. (Fabaceae) is a species found in the Atlantic rain forest of eastern Brazil. A decoction of $D$. ferruginea is drunk largely in the indigenous and folk medicine to treat inflammations and vaginal ulcers. It is also used in baths and washes external ulcers [20]. Previous chemical investigation has resulted in the isolation of flavonoids [21], benzenoids and a triterpene lupeol [22]. The flavonoid diplotropin isolated from $D$. ferruginea showed spasmolytic effect in guinea-pig ileum [23].

Several plant-derived secondary metabolites have been shown to interfere directly with molecules and mechanisms, such as the mediation of inflammatory responses and production/activity of second messengers, as well as with the expression of transcription factors and key pro-inflammatory molecules [24]. Triterpenes are regarded to be important as a potential natural source for medical compounds because of their wide range of biological activities [25]. Lupeol, a pentacyclic triterpene (Fig. 1), is a biologically active molecule that has received much attention due to its wide spectrum of medicinal properties

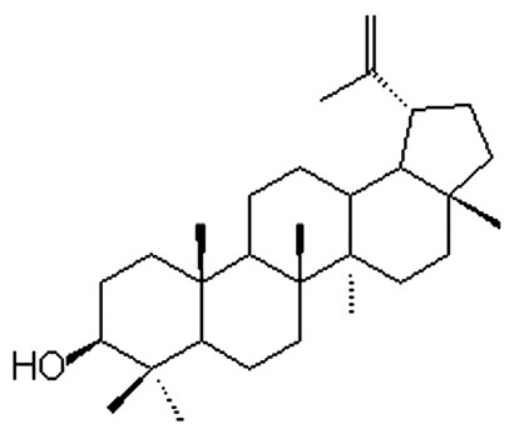

Figure 1 Chemical structure of lupeol. that include strong antioxidant, antimutagenic, anti-inflammatory and antiartheritic effects, both in vitro and in vivo [26-30]. In this paper we explored the activity of lupeol isolated from $D$. ferruginea in an animal model of allergic airway inflammation.

\section{Materials and methods}

\subsection{Plant material}

The stem-bark of $D$. ferruginea Benth. was collected in September 2005 near the city of Caraúbas in the state of Rio Grande do Norte, Brazil and identified by the botanist, Dr. Maria de Fátima Agra, from the Laboratory of Pharmaceutic Technology of the Federal University of Paraíba, PB, Brazil. A voucher specimen (Agra 5559) was authenticated and deposited at the Herbarium Prof. Lauro Pires Xavier (JPB), Department of Systematics and Ecology, Federal University of Paraíba, PB, Brazil.

\subsection{Extraction and isolation of lupeol}

The crude ethanol extract (CEE) was obtained according to Almeida et al. (2003). The dried and powdered stem-barks $(10 \mathrm{~kg})$ of $D$. ferruginea were extracted with $\mathrm{EtOH}$ (95\%), yielding, $413 \mathrm{~g}$ of crude ethanolic extract (CEE). The CEE was suspended in $\mathrm{H}_{2} \mathrm{O}$ and partitioned with hexane and $\mathrm{CHCl}_{3}$. The hexane extract $(55.6 \mathrm{~g})$ was dissolved in hot $\mathrm{MeOH}$ and left in a freezer for $24 \mathrm{~h}$, yielding a precipitate which, after recrystallization from hexane-methanol, yielded pure lupeol $(1.5 \mathrm{~g})$.

\subsection{Animals}

Male BALB/c mice, 4-6 weeks old, were used in the experiments. All animals were raised and maintained at the animal facilities of the Gonçalo Moniz Research Center, FIOCRUZ, BA, in rooms with controlled temperature $\left(22 \pm 2{ }^{\circ} \mathrm{C}\right)$ and humidity $(55 \pm 10 \%)$ and continuous air renovation. Animals were housed in a $12 \mathrm{~h}$ light $/ 12 \mathrm{~h}$ dark cycle $(6 \mathrm{am}-6 \mathrm{pm})$ and provided with rodent diet and water ad libitum. Animals were handled according to the NIH guidelines for animal experimentation. All procedures described here had prior approval from the local animal ethics committee.

\subsection{Sensitization and challenge with ovalbumin and treatment}

Groups of seven mice received systemic immunization by subcutaneous injection of $10 \mu \mathrm{g}$ of chicken egg ovalbumin (OVA; grade $\mathrm{V},>98 \%$ pure; Sigma, St Louis, MO) diluted in $2 \mathrm{mg} / \mathrm{ml}$ alum (Alumlmject; Pierce, Rockford, IL, USA) followed by a booster injection at day 14. A nasal challenge was performed starting at day 28 , by inhalational exposure to aerosolised ovalbumin for $15 \mathrm{~min} /$ day, on five consecutives days. Exposures were carried out in an acrylic box. A solution of $1 \%$ ovalbumin in saline was aerosolised by delivery of compressed air to a sidestream jet nebuliser (RespiraMax, NS, Brazil). Two hours before each aerosol delivery, mice were treated orally with lupeol $(60 \mathrm{mg} / \mathrm{kg})$, dexamethasone $(30 \mathrm{mg} / \mathrm{kg})$ or vehicle (10\% DMSO in saline).

\subsection{Collection of blood and bronchoalveolar lavage}

Twenty four hours after the last inhalational exposure, mice were anesthetized and bled via the brachial plexus for collection of blood samples used to estimate the IgE production. Bronchoalveolar lavage (BAL) was performed twice by intratracheal instillation of $1 \mathrm{ml}$ of 

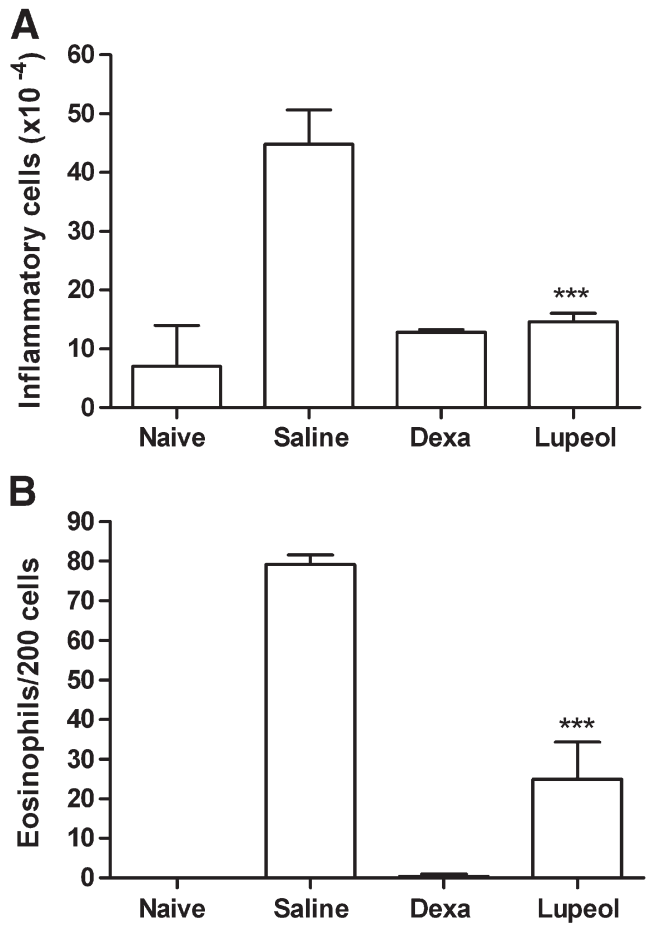

Figure 2 Leukocyte quantification in BAL samples obtained from mice submitted to different treatments. Mice were sacrificed $24 \mathrm{~h}$ after the last challenge with OVA. The cellularity in BAL fluid from normal or OVA-challenged mice treated with saline, dexamethasone (dexa) or lupeol was evaluated. (A) Total cell counts. (B) Number of eosinophils in 200 cells. Values are expressed as means \pm SEM of 6-7 mice per group, in one of two experiments performed.

PBS. The first lavage fluid was centrifuged, and aliquots of the supernatant were kept at $70{ }^{\circ} \mathrm{C}$ until use for cytokine measurements. The second lavage fluid was centrifuged and the two cell pellets were resuspended in a PBS final volume of $1 \mathrm{ml}$. The number of total leukocytes in BAL fluid was estimated in a Neubauer chamber. Cytospin slides were prepared from BAL fluid and stained with Giemsa stain. At least 200 cells were counted per slide under light microscopy and they were differentiated according to standard morphological criteria.

\subsection{Histopathological and morphometric analyses}

The right lobe of the lungs from each animal was removed for histological analysis. The lung was inflated via the tracheal cannula with $4 \%$ buffered formalin, fixed in the same solution, and embedded in paraffin. Sections were stained with hematoxylin and eosin for quantification of inflammatory cells by optical microscopy. For each lung 10 fields (400x) were analyzed per section, and the data used to calculate the mean number of cells per $\mathrm{mm}^{2}$. Mucus production was analyzed in periodic acid-Schiff (PAS)-stained sections. All images were digitalized using a color digital video camera (CoolSnap cf) adapted to a BX41 microscope (Olympus, Tokyo, Japan) calibrated with a reference measurement slide and were analyzed using Image Pro image program (version 6.1; Media Cybernetics, San Diego, CA, USA).

\subsection{OVA-specific antibody levels and cytokine production}

Immunoglobulin antibody levels to ovalbumin in sera samples from individual animals were quantified using an enzyme immunoassay modified from Jungsuwadee et al. (2004). For the measurement of OVA-specific IgG and IgG1, ELISA plates were coated with OVA at $10 \mu \mathrm{g} / \mathrm{ml}$ overnight at $4{ }^{\circ} \mathrm{C}$. The plates were washed and blocked with PBS 5\% non-fat milk for $1 \mathrm{~h}$ at room temperature. Sera diluted 1:100 were incubated for $2 \mathrm{~h}$ at room temperature. After washing, biotinylated anti-lgG1 or anti-lgG detection antibodies (American Qualex, San Clemente, CA, USA) were added and plates were incubated for $1 \mathrm{~h}$. After incubation with streptoavidin-peroxidase conjugate, the reaction was developed using 3,3\&prime;,5,5\&prime;tetramethylbenzidine (TMB) peroxidase substrate and read at $450 \mathrm{~nm}$. OVA-specific IgE titers were determined by coating plates with anti-

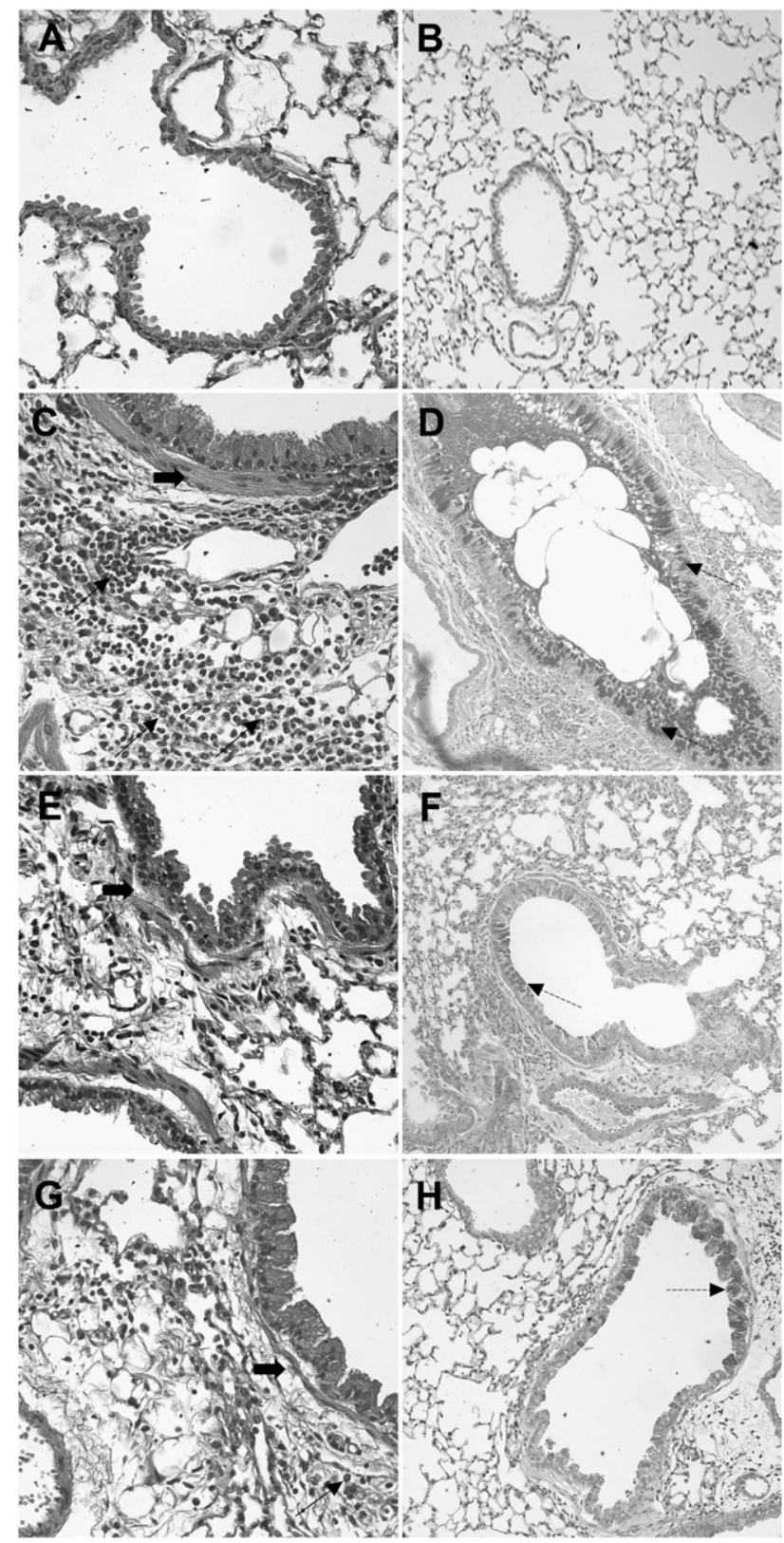

Figure 3 Histopathology of lungs from naïve and asthmatic mice. Lung sections of naïve $(A, B)$ and asthmatic mice treated with vehicle $(C, D)$, dexamethasone $(E, F)$, and lupeol $(G, H)$. Narrow arrows indicate eosinophils; large arrows indicate subepithelial fibrosis and prominent smooth muscle; dotted arrows indicate areas of $\mathrm{PAS}^{+}$cells. A, C, E, and G: H\&E, 400×. B, $\mathrm{D}, \mathrm{F}$, and $\mathrm{H}$ : PAS, 200×. 


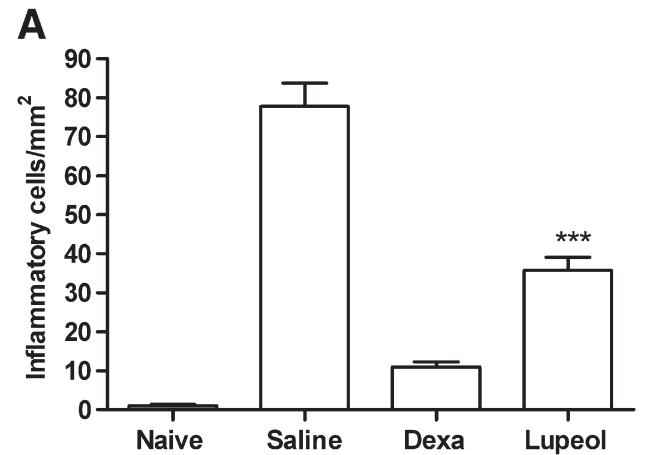

\section{B}

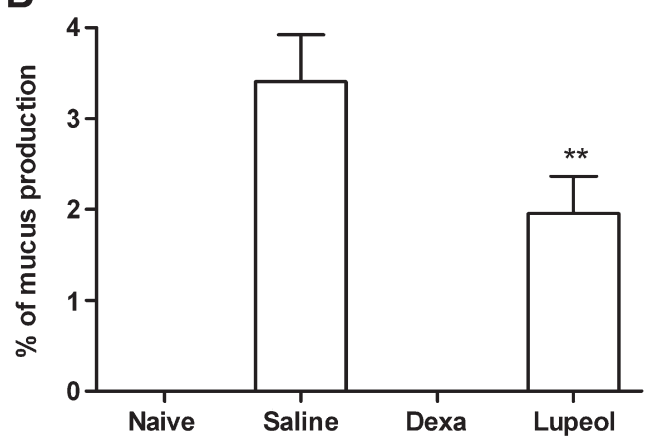

Figure 4 Quantification of inflammation and fibrosis in lungs of mice. (A) Intensity of inflammation in lungs of mice treated with saline, dexamethasone (dexa) or lupeol compared to naive animals. The number of inflammatory cells was evaluated on H\&E-stained sections. (B) Analysis of mucus production on PASstained lung sections. The area of PAS staining was estimated by morphometric analysis. Data are expressed as means \pm SEM of 7 mice per group, in one of two experiments performed.

mouse IgE (Pharmingem, San Diego, CA, USA) and detected with biotinylated-OVA (Fitzgerald, MA, USA). Concentrations of interleukin (IL)-4, IL-5 and IL-13 in BAL fluid were also determined by ELISA using specific antibody kits (R\&D System, Minneapolis, MN, USA), according to manufacturer's instructions.

\subsection{Statistical analysis}

Results were expressed as means \pm SEM of 7 mice per group. Statistical comparisons between groups were performed by analysis of variance (ANOVA) followed by Newman-Keuls multiple comparison test, using GraphPad InStat program (Software Inc., San Diego, (A, USA). Results were considered to be statistically significant when $P<0.05$.

\section{Results}

\subsection{Treatment with lupeol reduces lung inflammation}

To determine whether there were differences in lung inflammation between mice treated with lupeol and vehicle, BAL cytology was evaluated. The number of total BAL cells, which reflects the intensity of airway inflammation, was significantly reduced after lupeol treatment compared to vehicle-treated group (Fig. 2A). This inhibition was not statistically different from that caused by dexamethasone (about 3 -fold of vehicle-treated controls). Lupeol (60 mg/kg, p.o.) treatment also decreased significantly the number of eosinophils in the BAL, although the number of eosinophils in BAL from mice treated with dexamethasone was statistically lower than that of lupeol-treated mice (Fig. 2B).

\subsection{Histological evaluation of lungs from lupeol-treated mice}

To characterize further the changes in lung pathology caused by antigen challenge of immunized mice, we examined lung sections stained with H\&E. OVA challenge caused intense cell infiltrate containing many lymphocytes, macrophages and eosinophils (Fig. 3C). Mice treated with lupeol had reduced inflammation, particularly reduced eosinophil infiltration, although some less dense inflammatory foci remained (Figs. 3G and 4A). Dexamethasone treatment almost completely eliminated the inflammatory infiltrate, in particular eosinophils (Figs. 3E and 4A).

Lung sections were stained with PAS to analyze mucus overproduction. Lungs from naïve mice revealed rare $\mathrm{PAS}^{+}$cell in the respiratory epithelium compared to vehicle-treated

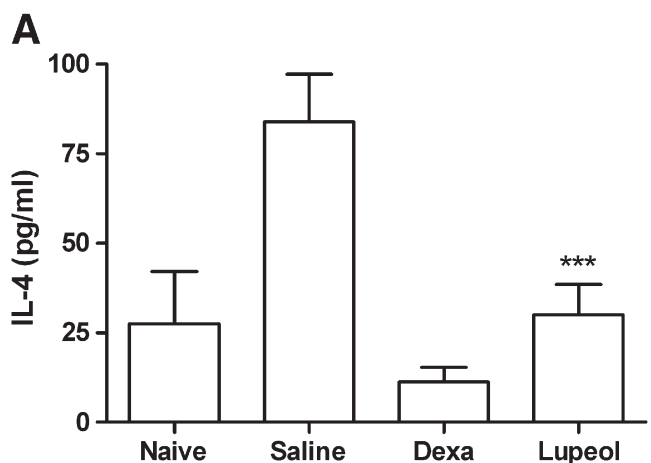

B
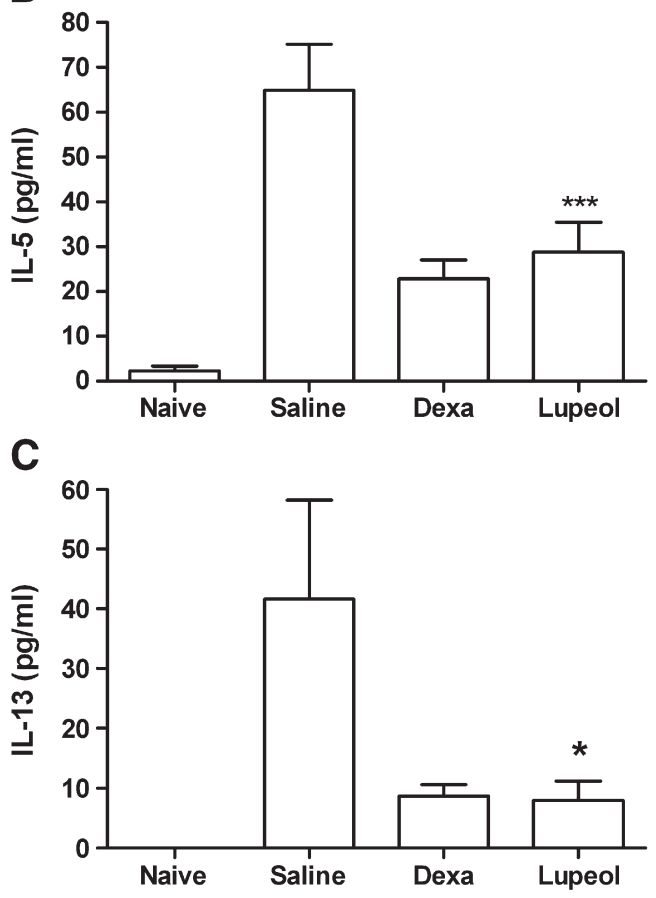

Figure 5 Decreased Type II cytokine production in lupeoltreated mice. IL-4 (A), IL-5 (B) and IL-13 (C) levels in individual mice from each experimental group were determined in $B A L$ samples by ELISA. Data are expressed as means \pm SEM of $6-7$ mice per group. ${ }^{*} P<0.05$ and ${ }^{* * *} P<0.01$. 


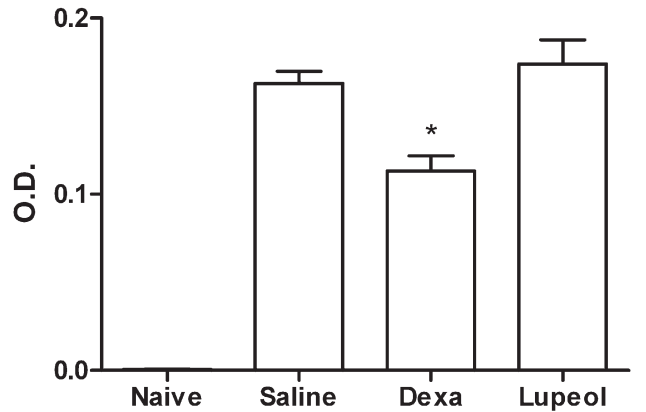

Figure 6 OVA-specific IgE antibodies in asthmatic mice. The levels of anti-OVA IgE antibodies were determined in serum samples from individual mice, by ELISA. The data are expressed as means \pm SEM of 7 mice per group, in one of two experiments performed.

group, which had high $\mathrm{PAS}^{+}$staining (Figs. 3B and D; 4). Similar to dexamethasone, lupeol treatment was capable of modulating mucus production, decreasing the $\mathrm{PAS}^{+}$staining observed in the vehicle-treated group by $44 \%$ (Figs. $3 \mathrm{~F}$ and $\mathrm{H}$; 4).

\subsection{Treatment with lupeol modulated T-helper type 2 cytokine response}

The production of cytokines in response to antigen challenge was studied in BAL fluid of individual mice from each group. As expected, the concentrations of Th2-associated cytokines IL-4, IL-5, and IL-13 were increased in OVA-immunized mice (Fig. 5). However, the levels of these cytokines were lower in lupeoltreated mice, compared to saline-treated group (two-fold for IL5, three-fold for IL-4 and four-fold for IL-13). Levels of cytokines in lupeol-treated animals were similar to those of dexamethasone-treated mice (Fig. 5).

Ova-immunized mice treated with vehicle had high serum levels of anti-OVA IgE antibodies (Fig. 6). Whereas a statistically significant reduction in OVA-specific IgE antibodies was observed in mice treated with dexamethasone, no difference was found in lupeol-treated mice as compared to saline-treated controls (Fig. 6). Levels of total IgG or IgG1 OVA-specific were similar in asthmatic mice treated with vehicle, dexamethasone or lupeol (data not shown).

\section{Discussion}

Lupeol is a triterpenoid purified from many plant species used in popular medicine, as well as in a great variety of fruits and vegetables [30]. It has been demonstrated that lupeol has anti-inflammatory properties in experimental model of arthritis and it suppressed superoxide generation by human neutrophils induced by aracdonic acid [27-29]. However, the anti-inflammatory activity of lupeol has never been studied in a model of allergic airway inflammation.

In the present study we demonstrated that lupeol had potent anti-inflammatory activity in an allergic airway inflammation model induced by OVA administration in mice. This was evidenced by a marked reduction in eosinophil numbers in BAL fluid and in the lung, in Th2-associated cytokine levels and in mucus production.

In our study no signs of toxicity were observed in lupeoltreated mice. Previous studies also found that this triterpe- noid did not cause any side effects even when administered in higher doses [27]. The fact that lupeol is present in a variety of edible fruits and vegetables also reinforces the potential safety of this substance for human use.

The effects of lupeol were similar to those of dexamethasone, a synthetic glucocorticoid commonly used as a gold standard anti-inflammatory drug. Glucocorticoids have a myriad of effects initiated by binding to their cytosolic receptors, translocating to the nucleus, and altering the regulation of inflammatory cytokine gene expression $[16,31]$. In allergic asthma, this results in the inhibition of macrophages, T-lymphocytes, eosinophils, and epithelial cells, reduced numbers of airway mast cells, reduced numbers of circulating and airway eosinophils, inhibit airway mucus secretion, and reduce histamine- and methacholineinduced airway responsiveness [13].

Lupeol reduced the production of PGE 2 , TNF- $\alpha$, and IL-1 $\beta$ in vitro [32], ear oedema induced by TPA in mice and paw swelling in an adjuvant arthritis model in rats [27]. The fact that lupeol does not show antinociceptive, anti-pyretic, and ulcerogenic effects indicate that this triterpene does not seem to act mainly by an inhibitory effect on PG synthetase, suggesting that the mechanism of anti-inflammatory action of lupeol is distinct from classical non-steroidal anti-inflammatory drugs [27].

In our study we observed effects similar to those of a glucocorticoid in an animal model of asthma. The demonstration that lupeol inhibits $\mathrm{PGE}_{2}$, but not leukotriene C4 production, from activated macrophages [32] suggests that lupeol acts by a mechanism distinct of glucocorticoids, which strongly inhibit leukotriene C4 production [33]. Thus, the identification of the mechanisms of lupeol action may be of relevance, since glucocorticoids, the most commonly used class of drugs in asthma treatment, have a number of side effects.

The inhibition of Type II cytokine production by lupeol suggests that this substance acts inhibiting T cells. In fact, lupeol inhibits mitogen-induced lymphocyte proliferation (our unpublished results). Since IL-5 promotes the differentiation to and activation of eosinophils, lupeol may cause the reduction of eosinophil infiltrates found in lupeol-treated asthmatic mice.

The results of the present study show that lupeol attenuates inflammation in a murine model of asthma. The effects described herein, as well as those observed by other investigators, together with the broad spectrum of the biological effects of this substance, strongly suggest that lupeol has therapeutic potential for the treatment of asthma and other allergic diseases.

\section{Acknowledgements}

This work had the financial support of FIOCRUZ, CNPq, Institutos do Milênio, IMSEAR, MCT, FINEP, RENORBIO and CAPES. The authors wish to thank Ricardo Santana de Lima and Daniele Brustolim for their technical assistance.

\section{References}

[1] Bukstein D, Kraft M, Liu AH, Peters SP. Asthma end points and outcomes: what have we learned? J Allergy Clin Immunol 2006;118:S1-S15.

[2] Reed CE. The natural history of asthma. J Allergy Clin Immunol 2006;118:543-8. 
[3] Zdanowicz MM. Pharmacotherapy of asthma. Am J Pharm Educ 2007;71:1-12.

[4] Global Initiative for asthma (GINA). Pocket guide for asthma management and prevention in children. National Institutes of Health, Lung and Blood Institute. Available at: http://www. ginasthma.com. Revised 2006.

[5] Corrigan CJ, Kay AB. Tcells and eosinophils in the pathogenesis of asthma. Immunol Today, 1992;13:501-7.

[6] Silveira MR, Nunes KP, Cara DC, Souza DG, Correa Jr A, Teixeira MM, Negrão-Correa D. Infection with Strongyloides venezuelensis induces transient airway eosinophilic inflammation, an increase in immunoglobulin $\mathrm{E}$, and hyperresponsiveness in rats. Infect Immun 2002;70:6263-72.

[7] El Biaze M, Boniface S, Koscher V, Mamessier E, Dupuy P, Milhe F, Ramadour M, Vervloet D, Magnan A. T cell activation, from atopy to asthma: more a paradox than a paradigm. Allergy 2003;58:844-53.

[8] Pawankar R. Mast cell function modulating IgE-mediated allergy. Allergol Int 1999;48:171-82.

[9] Temelkovski J, Hogan SP, Shepherd DP, Foster PS, Kumar RK. An improved murine model of asthma: selective airway inflammation, epithelial lesions and increased methacholine responsiveness following chronic exposure to aerosolized allergen. Thorax 1998;53:849-56.

[10] Ward C, Pais M, Bish R, Reid D, Feltis B, Johns D, Walters EH. Airway inflammation, basement membrane thickening and bronchial hyperresponsiveness in asthma. Thorax 2002;57: $309-16$.

[11] Homer RJ, Elias JA. Airway remodeling in asthma: therapeutic implications of mechanisms. Physiology 2005;20:28-35.

[12] Kilpiö K, Hannuksela M. Corticosteroid allergy in asthma. Allergy 2003;58:1131-5.

[13] Jungsuwadee P, Dekan G, Stingl G, Epstein MM. Inhaled dexamethasone differentially attenuates disease relapse and established allergic asthma in mice. Clin Immunol 2004;110: 13-21.

[14] Cardoso AP. Farmacologia dos broncodilatadores. Asma um grande desafio. São Paulo: Editora Atheneu; 2005.

[15] Schimmer BP, Parker KL. Adrenocorticotropic hormone; adrenocortical steroids and their synthetic analogs; inhibitors of the synthesis and actions of adrenocortical hormones. In: Hardman JG, Limbird LE, Goodman Gilman A, editors. The pharmacological basis of therapeutics. 10th ed. New York: McGraw-Hill; 2001.

[16] Barnes PJ. Corticosteroids, IgE, and atopy. J Clin Invest 2001;107: 265-6.

[17] Marinho MGV, Brito AG, Carvalho KA, Bezerra-Santos CR, Andrade LHC, Barbosa-Filho JM, Piuvezam MR. Amburana cearensis e cumarina imunomodulam os níveis de anticorpos antígeno-específico em camundongos BALB/c sensibilizados com ovalbumina. Acta Farm Bonaerense 2004;23: 47-52.

[18] Bezerra-Santos CR, Vieira-de-Abreu A, Barbosa-Filho JM, Bandeira-Melo C, Piuvezam MR, Bozza PT. Anti-allergic properties of Cissampelos sympodialis and its isolated alkaloid warifteine. Int Immunopharmacol 2006;6:1152-60.
[19] Costa HF, Bezerra-Santos CR, Barbosa-Filho JM, Martins MA, Piuvezam MR. Warifteine, a bisbenzylisoquinoline alkaloid, decreases immediate allergic and thermal hyperalgesic reactions in sensitized animals. Int Immunopharmacol in press.

[20] Agra MF, França PF, Barbosa-Filho JM. Synopsis of the plants known as medicinal and poisonous in Northeast of Brazil. Rev Bras Farmacogn 2007;17:114-40.

[21] Almeida JRGS, Barbosa-Filho JM, Cabral AGS, Agra MF, Cunha EVL, Silva MS, Nascimento SC, Braz-Filho R. Diploflavone, a new flavonoid from Diplotropis ferruginea Benth. (Fabaceae). J Braz Chem Soc 2005;16:1454-7.

[22] Almeida JRGS, Cunha EVL, Silva MS, Athayde-Filho PF, BrazFilho R, Barbosa-Filho JM. Outros constituintes químicos de Diplotropis ferruginea Benth (Fabaceae). Rev Bras Farmacogn 2003;14:44-6.

[23] Lima JT, Almeida JRGS, Barbosa-Filho JM, Assis TS, Silva MS, Cunha EVL, Braz-Filho R, Silva BA. Spasmolytic action of diplotropin, a furanoflavan from Diplotropis ferruginea Benth., involves calcium blockade in guinea-pig ileum. Z Naturforsch 2005;60b:1093-100.

[24] Calixto JB, Campos MM, Otuki MF, Santos ARS. Anti-inflammatory compounds of plant origin. Part II. Modulation of proinflammatory cytokines, chemokines and adhesion molecules. Planta Med 2003;69:973-83.

[25] Sparg SG, Light ME, van Staden J. Biological activities and distribution of plant saponins. J Ethnopharmacol 2004;94:219-43.

[26] Nagaraj M, Sunitha S, Varalakshmi P. Effect of lupeol, a pentacyclic triterpene, on the lipid peroxidation and antioxidant status in rat kidney after chronic cadmium exposure. J Appl Toxicol 2000;20:413-7.

[27] Geetha T, Varalakshmi P. Anti-inflammatory activity of lupeol and lupeol linoleate in rats. J Ethnopharmacol 2001;76:77-80.

[28] Sunitha S, Nagaraj M, Varalakshmi P. Hepatoprotective effect of lupeol and lupeol linoleate on tissue antioxidant defence system in cadmium-induced hepatotoxicity in rats. Fitoterapia 2001;72:516-23.

[29] Yamashita K, Lu H, Lu J, Chen G, Yokoyama T, Sagara Y, Manabe $M$, Kodama $H$. Effect of three triterpenoids, lupeol, betulin, and betulinic acid on the stimulus-induced superoxide generation and tyrosyl phosphorylation of proteins in human neutrophils. Clin Chim Acta 2002;325:91-6.

[30] Sallem M, Kweon M, Yun J, Adhami VM, Khan N, Syed DN, Mukhtar $\mathrm{H}$. A novel dietary triterpene lupeol induces Fas-mediated apoptotic death of androgen-sensitive prostate cancer cells and inhibits tumor growth in a xenograft model. Cancer Res 2005;65 (23): 11203-13.

[31] Boyton RJ, Altmann DM. Asthma: new developments in cytokine regulation. Clin Exp Immunol 2004;136:13-4.

[32] Fernández MA, de las Heras B, García MD, Sáenz MT, Villar A. New insights into the mechanism of action of the anti-inflammatory triterpene lupeol. J Pharmacol 2001;53(11):1533-9.

[33] Castro CM, Bureau MF, Nahori MA, Dumarey $\mathrm{CH}$, Vargaftig BB, Bachelet M. Modulation by dexamethasone of phospholipase A2 activities in endotoxemic guinea pigs. J Appl Physiol 1995;79:1271-7. 